\title{
Victorian healthcare experience survey 2016-2018; evaluation of interventions to improve the patient experience
}

\author{
Eunice Wong ${ }^{1,2^{*}}$, Felix Mavondo ${ }^{3}$, Lidia Horvat ${ }^{4}$, Louise McKinlay ${ }^{4}$ and Jane Fisher $^{2}$
}

\begin{abstract}
Background: Patient experience is recognised as a quality of care indicator and increasingly health services are working on achieving set targets and improving their performance. Interventions at the point of care targeting communication with patients, patient engagement in care processes and discharge planning are associated with better patient experience. However, their efficacy and application to different contexts are still unclear. The aims were to describe the interventions implemented by health services to improve patient experience, their impact on overall patient experiences and specific experiences in areas of communication, discharge planning, patient education on treatment/tests, the physical environment and access to care.
\end{abstract}

Methods: Secondary data analysis of the Victorian Healthcare Experience inpatient surveys reported in September 2016 and 2018 and content analysis of interventions published in the Victorian Quality Account for 2017 from 59 public health services in Victoria, Australia. The interventions were categorised using an adapted taxonomy of professional interventions by the Cochrane EPOC Review Group. Univariate tests and confirmatory factor analysis were conducted to test measure invariance across the 2016 and 2018 groups and examine the association between each of the intervention categories on overall patient experience measure and specific outcome measures.

Results: This study found that the overall patient experience was consistent (93\%) between 2016 and 2018 samples. In comparing impact, a single intervention rather than none or multiple interventions in communication, respect and dignity and treatment and disease education areas were associated with a higher level of the overall patient experience. Interventions in waiting time, access to service, care continuity and emotional support categories were associated with a decrease in overall patient experience.

Conclusion: This study found that to improve the overall patient experience, more focus is needed on evidencebased interventions in dignity and respect and emotional support. Furthermore, the choice of interventions should be guided by evidence of their efficacy and prioritising implementing one intervention well, provides more gains.

Keywords: Patient experience survey, Patient experience, Public hospital, Interventions, Australia

\footnotetext{
* Correspondence: eunice.wong@monash.edu

'BehaviourWorks Australia, Monash Sustainable Development Institute,

Monash University, Melbourne, PO Box 8000, Monash University LPO,

Clayton, VIC 3800, Australia

${ }^{2}$ School of Public Health and Preventive Medicine, Monash University,

Melbourne, Australia

Full list of author information is available at the end of the article
}

(C) The Author(s). 2021 Open Access This article is licensed under a Creative Commons Attribution 4.0 International License, which permits use, sharing, adaptation, distribution and reproduction in any medium or format, as long as you give appropriate credit to the original author(s) and the source, provide a link to the Creative Commons licence, and indicate if changes were made. The images or other third party material in this article are included in the article's Creative Commons licence, unless indicated otherwise in a credit line to the material. If material is not included in the article's Creative Commons licence and your intended use is not permitted by statutory regulation or exceeds the permitted use, you will need to obtain permission directly from the copyright holder. To view a copy of this licence, visit http://creativecommons.org/licenses/by/4.0/ The Creative Commons Public Domain Dedication waiver (http://creativecommons.org/publicdomain/zero/1.0/) applies to the data made available in this article, unless otherwise stated in a credit line to the data. 


\section{Background}

Patient experience is commonly defined as the range of interactions that patients have with the health care system, their care from health plans, and doctors, nurses, and staff in hospitals, physician practices and other health care facilities [1-3]. Consistent positive associations have been found between good patient experiences and clinical benefits (i.e. health outcomes, adherence to medications, and increased self-management) [4-7] and with healthcare cost reductions in areas such as reduced readmissions and length of stay [8-10].

This acknowledgment of patient experience as a key quality indicator of healthcare is reflected in the growing literature on the efficacy of interventions. Studies on systematic collection of patient experience surveys [11-14], reported trends suggesting improvement; however, there was no clarity on what contributed to the improvements in the patient experience.

\section{Interventions targeting patient experience}

To date, interventions implemented at the point of care, targeting communication with patients, patient engagement in care processes and discharge planning were found to be associated with better patient experience outcomes. This suggests that interventions at the point of care, with a direct link to how patients experience the care delivery, could be more effective, as patient experience measures were designed and focused on what happens during the health care delivery interaction.

Interventions targeting attitudes of health professionals, patient/carer involvement and clinicianpatient communication, at the point of care delivery were found to have the most significant impact on patient experience [15]. This was further supported by a qualitative study exploring patients' perspectives where communication with and between patients and staff, interpersonal relationships with staff; engagement in care and discharge planning and the hospital environment determined a positive or negative patient experience [16]. The acknowledgement of the importance of clinician-patient communication and interpersonal skills has spurred the body of evidence in these areas. Studies in general communication training and patient education [17, 18] found that they are positively associated with the level of the patient experience. In contrast, a study on specific communication training for clinical consultations [19] found increased skill acquisition for health professionals, but the effect on patient experience was not rigorously evaluated. This suggests that while the relationship between these interventions and the patient experience was established, their efficacy and mechanism of action in different contexts are unclear.

\section{Patient experience}

Patient experience measures are designed to find out what actually happens during the health care interaction, whether specific patient-centred care behaviours are carried out. These measures are collected through quantitative and qualitative approaches. Quantitative data may be collected through ward or hospital or national surveys. Qualitative data from interviews, focus groups, written and or video recording of patient stories on websites and observation and shadowing of patients. Each of these approaches has its strengths and limitations, and it is suggested that the triangulation of qualitative and quantitative studies is needed for a comprehensive understanding of patient experience [20, 21]..

Despite their limitations, patient experience surveys are preferred where the collection of standardised data from large representative patient populations for benchmarking is needed [22]. For example, the Picker Patient Experience Questionnaire [23] and the Hospital Consumer Assessment of Healthcare Providers and Systems (HCAHPS) used in the U.S. included questions about communication with nurses and doctors, interaction with other hospital staff (i.e. allied health, ancillary staff), the hospital environment, pain management, patient education, discharge process, overall experience and patient demographic characteristics.

These have been implemented in many countries. For example, in the UK, the National Health Service (NHS) introduced a national reporting system for surveys of patient experiences and reports publicly on service-level data $[10,24]$. In the United States (US), standardised, national data on patient experience has been collected and reported publicly since 2011 . In their efforts to improve patient care, Canada, Denmark, and the Netherlands have also established systems for collecting and publishing patient experiences measures [25-27].

\section{Aims of the study}

With public reporting and the recognition of patient experience as a health service's performance measure, health service providers are increasingly focused on improving patient experience. However, the evidence on interventions was limited by the lack of well-designed evaluation studies beyond single sites [28].

This study aimed to address this gap by evaluating the interventions used by public health services in Victoria to improve the experience of their patients, as indicated in outcome measures. First, to evaluate the target areas of the interventions and their individual and combined effects on the overall patient experience outcome measure. Second, the effects of the interventions on specific outcome measures of staff-patient communications, discharge planning, respect and dignity for patients, 
emotional support for patients, education of treatment/ tests and the physical environment.

\section{Methods}

\section{Design}

This study is a secondary analysis of the Victorian Healthcare Experience Survey (VHES) [29] data for 2018, after the introduction of new reporting guidelines for improving patient experience in 2017. Surveys reported in September 2016 and September 2018 and the publicly available annual Victorian Quality Account [30] for 2017 from public health services in Victoria, Australia. Data from the VHES were provided to the investigators following completion of a standard application to Safer Care Victoria and the Victorian Agency for Health Information.

\section{Setting \& study population}

Victoria is the second most populous state in Australia with a population of 6.6 million people, most of whom (4.9 million people) live in the metropolitan and greater Melbourne area. Australia has a two-tier health system of public and private health services, where the funding and service delivery is shared between the Australian Federal government and the State governments. The Victorian state government is responsible for funding and managing public hospitals, regulating and licensing private hospitals, amongst other primary health and preventive services [31].

This study targeted public health services in Victoria that met the following criteria: (i) they had Victorian Healthcare Experience Survey (VHES) data for inpatients aged 18 years and above reported in September 2016 and September 2018 and (ii) had publicly available annual Victorian Quality Account for 2017.

\section{Sources of data \\ Victorian quality account}

The Victorian Quality Account is a mandatory annual report where public health services are required to provide a qualitative description of the systems, processes and interventions used to fulfil various safety and quality indicators [32]. The individual health service reports were published on the Department of Health and $\mathrm{Hu}-$ man Services (DHHS) Victoria website and individual health services' websites. From 2017, with additional focus on patient experience, health services were required to report and describe the interventions taken to improve patient experience scores collected by the VHES [32]. As such, the Victorian Quality Account serves as a high quality source of data on interventions used by health services.

\section{Victorian healthcare experience survey}

The Victorian Healthcare Experience Survey (VHES) is a state-wide survey of patients' public healthcare experiences required by the Department of Health and Human Services (DHHS) Victoria and is based on the internationally recognised work of the Picker Institute [29]. At the time of this study, surveys were administered to 10 patient categories: adult inpatients, adult emergency, maternity patients, paediatric inpatients, paediatric emergency, adult specialist clinics, paediatric specialist clinics, community health services, planned and emergency ambulance service and palliative care clients. The surveys were conducted monthly with adult inpatients, adult emergency and maternity patients and annually for the remaining seven patient categories [33].

In this study, the adult inpatient VHES surveys of 2016 and 2018 were selected as they included all health conditions. The adult inpatient VHES survey had a total of 92 questions.

\section{Data management \\ Qualitative description of interventions}

The Victorian Quality Account 2018 reported details of interventions undertaken by the health service to address patient experience scores (measured by VHES). The Victoria Quality Accounts 2018 for the 59 health services were searched and downloaded from their respective official websites and cross-checked with the copy on the DHHS website. The dedicated section of the Victorian Quality Account, which focused on interventions for improving patient experience was extracted and analysed for each health service.

Documents, programs and policies and periodic reports were analysed using a five-step process; access, check validity, comprehend, analyse and apply the information in the form of extracted themes [34]. Content analysis was conducted using a deductive approach. Themes that emerged were assigned into the following intervention categories; patient-staff communication, staff-staff communication, respect and dignity, emotional support, integration of care, care continuity, discharge planning, treatment and disease education, waiting time and access and physical environment. These intervention categories were adapted from a taxonomy of professional interventions by the Cochrane Effective Practice and Organisation of Care (EPOC) Review Group [35] and a previous study [28] (see Additional file 1 for details).

Cross-case synthesis [36] was performed aggregating the themes that emerged into categories.

Before coding commenced, intervention categories and definitions were discussed and clarified. The excerpts from the Victorian Quality Accounts were coded for the presence and absence of the themes. The Kappa index was calculated for $10 \%$ of the health services (randomly 
selected) to determine the inter-rater reliability. In these, the extracted sections were coded by two coders independently. After the inter-rater reliability comparison, discrepancies were resolved by discussion and the remaining health services' Quality Account reports were coded independently by one coder. All content analysis and coding of interventions from the Victorian Quality Account reports were completed before analysis of the VHES dataset to reduce a potential source of bias in coding if there was prior knowledge of any differences or trends in the VHES from 2016 and 2018.

The next step was to include and apply the categorical data of interventions to the quantitative data from VHES. This frequency distribution lists the number of occurrences for each category of intervention used by each of the 59 health services was created and added to the VHES dataset as additional intervention variables.

\section{Quantitative data for outcome measures}

The data for this study were pooled from raw unweighted responses from patients who were discharged from the services during the periods of April-June 2016 and April-June 2018, published in September 2016 and September 2018, respectively.

The VHES used a combination of three, four and fivepoint Likert response scale across the questions in the survey. Before data analysis, to standardise the response scale, the VHES survey responses were transformed to a universal 0-100 scale [37] with higher scores indicating a more positive response.

The relevant VHES survey questions were grouped into seven outcome measures, assessing the performance in the key patient experience areas of overall patient experience, communication, respect and dignity, emotional support, discharge planning, treatment and disease education and physical environment (see Additional file 2 for details).

\section{Overall patient experience measure}

The overall patient experience consisted of only one question in the VHES survey and enquired 'Overall, how would you rate the care you received while in hospital?' This measure was also used by the DHHS of Victoria as part of their performance monitoring and with the target set at $95 \%$ for public health services [38].

\section{Communication experience measure}

This measure consisted of six VHES questions regarding communication between staff and patient to assess the quality of communication experience.

\section{Respect, dignity and emotional support measures}

These measures assessed the level of respect and dignity (4 questions) and emotional support (5 questions) reported on the VHES questions. The questions categorised under these measures include those about respect, emotional support, the decision about care and privacy.

\section{Discharge planning measure}

The experience of care management in preparation for discharge was assessed by this measure, which consisted of four VHES questions. This measure was also used by the DHHS Victoria as part of their performance monitoring and with the target set at $75 \%$ for public health services [38].

\section{Treatment and disease education measure}

VHES questions (4 questions) about information provided to patients about their treatments, tests and operations were categorised into this measure.

\section{Physical environment measure}

This measure assessed the experience of the physical environment, VHES questions (2 questions) related to the cleanliness of hospital and ward environments were included.

\section{Statistical analysis}

Descriptive analyses and univariate tests of betweengroup differences were conducted on the responses from the two VHES surveys (2016 and 2018). Confirmatory factor analysis on the VHES items that made up the outcome measures across the response groups from 2016 and 2018 [39] was conducted to test measurement invariance across the two cohorts groups. This analysis was conducted to examine whether respondents from both years interpret the VHES in equivalent ways [40, 41]. Measure invariance follows a sequence of steps. The first step is to establish configural equivalence. This is a baseline measure establishing that the same latent variables are being mapped in the two samples and that each latent variable has the same indicators. The second step is to constrain the regression weights of the indicators to be correspondingly equal across the 2016 and 2018 samples. This model is compared to the baseline to assess the degree of model worsening as a result of assuming equality of regression weights. If worsening is not significant, then metric equivalence is supported. The next step is to constrain the intercepts to equality (strong equivalence). This is then compared to the metric equivalence model. If the model statistics do not significantly worsen strong equivalence is supported, and any additional constraints will not invalidate the conclusion that there is measure equivalence/invariance.

The internal consistency of the outcome measures was established through the Cronbach alpha. The 
relationships among the variables are investigated using correlation coefficients and regression coefficients.

The association between each of the intervention categories (use and number of interventions) reported in 2017, and overall patient experience measure and other outcome measures in 2018 were examined using t-tests for dichotomous measures and one-way ANOVA for interventions with three or more levels with data from 2018. Finally, multiple regression was conducted to assess the contribution of the combination of related interventions to the overall patient experience measure. The data were compiled and analysed using IBM SPSS V.26 and AMOS V.26.

\section{Ethics approval}

Ethics approval for this study was provided by the Monash University Human Research Ethics Committee (Project ID 20530).

\section{Results}

\section{Sample characteristics}

Data were contributed by 7709 respondents from the 2016 survey and 7497 respondents from 2018 survey (total $n=15,206$ ). The mean ages of the 2016 and 2018 survey respondents were 64.3 years $(\mathrm{SD}=17.1)$ and 65.9 years $(\mathrm{SD}=16.5)$, respectively. The age in both 2016 and 2018 surveys had moderately negatively (left) skewed distributions. Details of the mode of hospital stay and category of health services are shown in Table 1. In both years, the metropolitan health services form the majority of the data.

\section{Trends in patients experience scores between 2016 and 2018}

There were 56 questions from the VHES with Likert type response scale; they were standardised, and mean scores were calculated for the overall patient experience

Table 1 Mode of Hospital Admission and Category of Health Services

\begin{tabular}{lll}
\hline Characteristics & $\mathbf{2 0 1 6}$ & $\mathbf{2 0 1 8}$ \\
\hline & $n(\%)$ & $n(\%)$ \\
Hospital stays & & $3978(53.1)$ \\
Planned in advance & $3994(51.8)$ & $2717(36.2)$ \\
Emergency & $2887(37.4)$ & $470(6.3)$ \\
Other & $473(6.1)$ & $332(4.4)$ \\
Missing & $355(4.6)$ & \\
Categories of Health Services & & $3071(41.0)$ \\
Metro & $3119(40.5)$ & $1866(24.9)$ \\
Regional & $1965(25.5)$ & $2228(29.7)$ \\
Rural & $2270(29.4)$ & $332(4.4)$ \\
Missing & $355(4.6)$ & \\
\hline
\end{tabular}

measure and specific outcome measures. Internal consistency was checked for each set of questions, only those with Cronbach's alpha ( $\geq 0.7)$, were used for further analysis as specific outcome measures. No valid set of questions for staff-staff communication, integration of care, waiting time and access, and care continuity were found and as such outcome measures in these areas were not included in the analysis (see Additional file 2 for list of questions).

There were strong positive correlations between the specific outcome measures of discharge planning, patient-staff communication, respect and dignity, emotional support and treatment and disease education outcome measures with the exception of the physical environment. (see Table 2).

The overall patient experience measure for 2016 responses $(\mathrm{M}=93.4, \mathrm{SD}=13.1)$ and 2018 responses $(\mathrm{M}=$ 93.6, $\mathrm{SD}=12.9$ ) was consistent between the 2 years. Despite no difference in the overall patient experience measure between 2016 and 2018 responses, the patient-staff communication measure and respect \& dignity measure has increased mean scores indicating an improvement in those areas. On further examination nine out of 56 VHES questions also had increased mean scores, indicating an improvement in those areas. Notably, the same five questions had the lowest scores in 2016 and 2018, suggesting potential areas such as involvement in discharge planning and communication with doctors and caregivers to focus on for future interventions (See Table 3 for details).

Statically significant differences at $p<.01$ in the overall experience measure were found in comparing metropolitan, regional and rural health services in both 2016 and 2018 responses. Overall patient experience mean score of rural health services were higher than those of the regional and metropolitan health services for both years. However, the difference in mean score and effect size (eta squared $=.03$ ) was small. The statistical difference between the categories of gender identification (Male, Female) was found only in the 2018 responses, with a small magnitude of differences in the means (eta squared $=.003$ ). As such, further analysis based on these group differences were not conducted. See Table 4 for full details.

\section{Frequency of interventions reported by health services in 2017}

There were between one to four interventions coded for each of the health services, with reliability using Kappa index $(K=0.8)$. As depicted in Fig. 1, intervention categories most frequently reported were physical environment, followed by patient-staff communication and discharge planning. It is noted that patient-staff communication outcome measure were one of the measures 
Table 2 Correlations of Specific Outcome Measures

\begin{tabular}{|c|c|c|c|c|c|c|c|}
\hline Outcome Measures & Cronbach's a (No. of Qs) & 1 & 2 & 3 & 4 & 5 & 6 \\
\hline 1. Discharge Planning & $0.8(4)$ & 1 & & & & & \\
\hline 2. Physical Environment & $0.8(2)$ & .534 & 1 & & & & \\
\hline 3. Patient-Staff Communication & $0.8(6)$ & .847 & .569 & 1 & & & \\
\hline 4. Respect \& Dignity & $0.7(4)$ & .769 & .647 & .913 & 1 & & \\
\hline 5. Emotional support & $0.8(5)$ & .820 & .604 & .983 & .988 & 1 & \\
\hline 6. Treatment \& Disease Education & $0.7(4)$ & .781 & .474 & .863 & .720 & .805 & 1 \\
\hline
\end{tabular}

with an increased in mean scores between 2016 and 2018, suggesting an improvement in this area.

\section{Measure invariance of 2016 and 2018 cohort}

Testing for measurement invariance ensures that the comparison across the 2016 and 2018 cohorts were both meaningful and valid. The baseline model had $x^{2}$ $(154)=2962.00 ; p<0.001 ; x^{2} ;$ df ratio of 19.33 ; the
RMSEA $=0.04$ and the NFI, CFI and TLI all above 0.9 (see Table 5). Having established the baseline, testing for weak factorial invariance was conducted by constraining factor loading matrices. The result of $\Delta x^{2}(\Delta d f)$ is 4.26; $p$ $<0.005$ for Model 1 showed some improvement from the baseline model, and the RMSEA improved with NFI, TLI, CFI consistent. The next step was conducted on testing for strong equivalence by adding additional

Table 3 Mean scores on VHES questions in 2016 and 2018 responses

\begin{tabular}{|c|c|c|c|}
\hline Outcome measures with significant differences between 2018 and 2016 & $\begin{array}{l}\text { Mean } \\
(2018) \\
(2016)\end{array}$ & Score & $t$ \\
\hline Overall patient experience & 93.60 & 93.36 & 1.12 \\
\hline Discharge planning & 80.77 & 79.95 & $1.68^{+}$ \\
\hline Physical environment & 93.72 & 93.45 & 1.32 \\
\hline Patient-Staff communication & 87.75 & 87.01 & $2.07^{*}$ \\
\hline Respect \& dignity & 94.20 & 93.59 & $2.93^{* * *}$ \\
\hline Emotional support & 89.45 & 88.53 & $1.76^{+}$ \\
\hline Treatment \& disease education & 86.26 & 86.13 & 0.22 \\
\hline VHES questions with significant differences between 2016 and 2018 & $\begin{array}{l}\text { Mean } \\
(2018) \\
(2016)\end{array}$ & Score & $t$ \\
\hline How would you rate the politeness and courtesy of admissions staff? & 95.44 & 94.90 & $3.09^{* *}$ \\
\hline Did you feel friends and family were welcome to visit you? & 97.26 & 96.50 & $2.91^{* *}$ \\
\hline Were the nurses treating you compassionately? & 94.76 & 93.96 & $2.86^{* *}$ \\
\hline Were the doctors treating you compassionately? & 92.95 & 92.18 & $2.32^{*}$ \\
\hline If you needed to talk to a nurse, did you get the opportunity to do so? & 89.54 & 88.46 & $2.79^{* *}$ \\
\hline How would you rate how well the doctors and nurses worked together? & 86.97 & 86.27 & $2.65^{* *}$ \\
\hline Did you see hospital staff wash their hands, use hand gel to clean their hands, or put on clean gloves before examining you? & 90.80 & 89.54 & $3.01^{* *}$ \\
\hline Do you think the time you had to wait from arrival until you were taken to your room or ward was? & 88.35 & 87.22 & $2.52^{*}$ \\
\hline At other times during your hospital stay did you have enough privacy? & 90.52 & 89.57 & $2.47^{*}$ \\
\hline VHES questions with lowest scores & $\begin{array}{l}\text { Mean } \\
(2018) \\
(2016)\end{array}$ & Score & $t$ \\
\hline If you needed to talk to a doctor, did you get the opportunity to do so? & 82.22 & 81.43 & 1.44 \\
\hline How would you rate the hospital food? & 79.60 & 79.28 & 0.88 \\
\hline Did you feel you were involved in decisions about your discharge from hospital? & 77.61 & 76.23 & $2.30^{*}$ \\
\hline How much information about your condition or treatment was given to your family, carer or someone close to you? & 69.08 & 70.01 & 1.15 \\
\hline Did you receive copies of communications sent between hospital doctors and your GP? & 66.90 & 66.03 & 1.42 \\
\hline
\end{tabular}

${ }^{*}=p<.05$, two-tailed. ${ }^{* *}=p<.01$, two-tailed. ${ }^{* * *}=p<.00$, two-tailed. ${ }^{+}=p<.05$, one-tailed 
Table 4 One-Way ANOVA of Category of Health Services and Gender Identification on Overall Patient Experience

\begin{tabular}{|c|c|c|c|c|c|}
\hline \multicolumn{6}{|c|}{ One-Way ANOVA } \\
\hline & (A) Metropolitan M (SE) & (B) Regional M (SE) & (C) Rural M (SE) & F-ratio & Differences \\
\hline 2016 & $91.10(.261)$ & $93.45(.297)$ & $96.41(.193)$ & $114.03^{* * *}$ & $C>B>A$ \\
\hline 2018 & $91.37(.262)$ & $93.60(.293)$ & $96.67(.197)$ & $114.45^{* * *}$ & $C>B>A$ \\
\hline T-Test & (A) Male M (SE) & (B) Female M (SE) & & $t$ & Differences \\
\hline 2016 & $93.60(.232)$ & $93.18(.210)$ & & 1.33 & - \\
\hline 2018 & $94.39(.218)$ & $92.93(.219)$ & & $4.67^{* * *}$ & $A>B$ \\
\hline
\end{tabular}

${ }^{*}=p<.05,{ }^{* *}=p<.01,{ }^{* * *}=p<.001$

constraints on Model 2 where the elements of the intercept matrices were constrained. The result of $\Delta x^{2}(\Delta d f)$ is $1.74 ; p<$ 0.051 showed Model 2 improved in fit when assuming intercepts are equal. Further testing for strict factorial invariance by constraining the errors terms was conducted. The result of $\Delta x^{2}(\Delta d f)$ is $6.30 ; p<0.001$ showed the Model 3 further improved when error terms are assumed equal. The testing for elegant factorial invariance showed that Model 4 with $\Delta x^{2}(\Delta d f)$ is $3.83 ; p<0.001$ is a good fit with RMSEA, NFI, TLI, CFI were consistent with Model 3. The finding supports that the respondents from 2016 and 2018 interpreted the VHES survey measure in a conceptually similar way.

\section{Association between interventions and VHES}

The impact of these interventions was assessed firstly on the overall patient experience measure and subsequently on outcome measures derived from measuring specific aspects of care: 1) communication, 2) respect and dignity, 3) emotional support, 4) discharge planning, 5) treatment and disease education and

6) physical environment measure.

\section{Impact of individual intervention category on overall patient experience measure}

The differences on the overall patient experience measure associated with the number of interventions applied are shown in Table 6. There were significant differences with the application of integration of care interventions $(p<.001)$ Two interventions were significantly better than one intervention which in turn was better than no intervention in improving overall patient experience. Care integration often involves changing existing clinical practices and processes across teams, and the result suggests that effective outcomes may require several coordinated interventions. There was no significant difference as a result of implementing discharge planning interventions.

Application of one intervention for staff-staff communication and patient-staff communication showed significant differences $(p<.001)$ being higher scores than no intervention and two interventions. Similarly, for respect and dignity and treatment and disease education, significantly higher scores were found with one intervention compared to none. This suggests a carefully targeted intervention in staff-staff communication, patientstaff communication, respect and dignity and treatment and disease education could lead to a significant increase in overall patient experience score.

Overall patient experience measure did not increase with the use of waiting time and access to service, care continuity and emotional support interventions; no

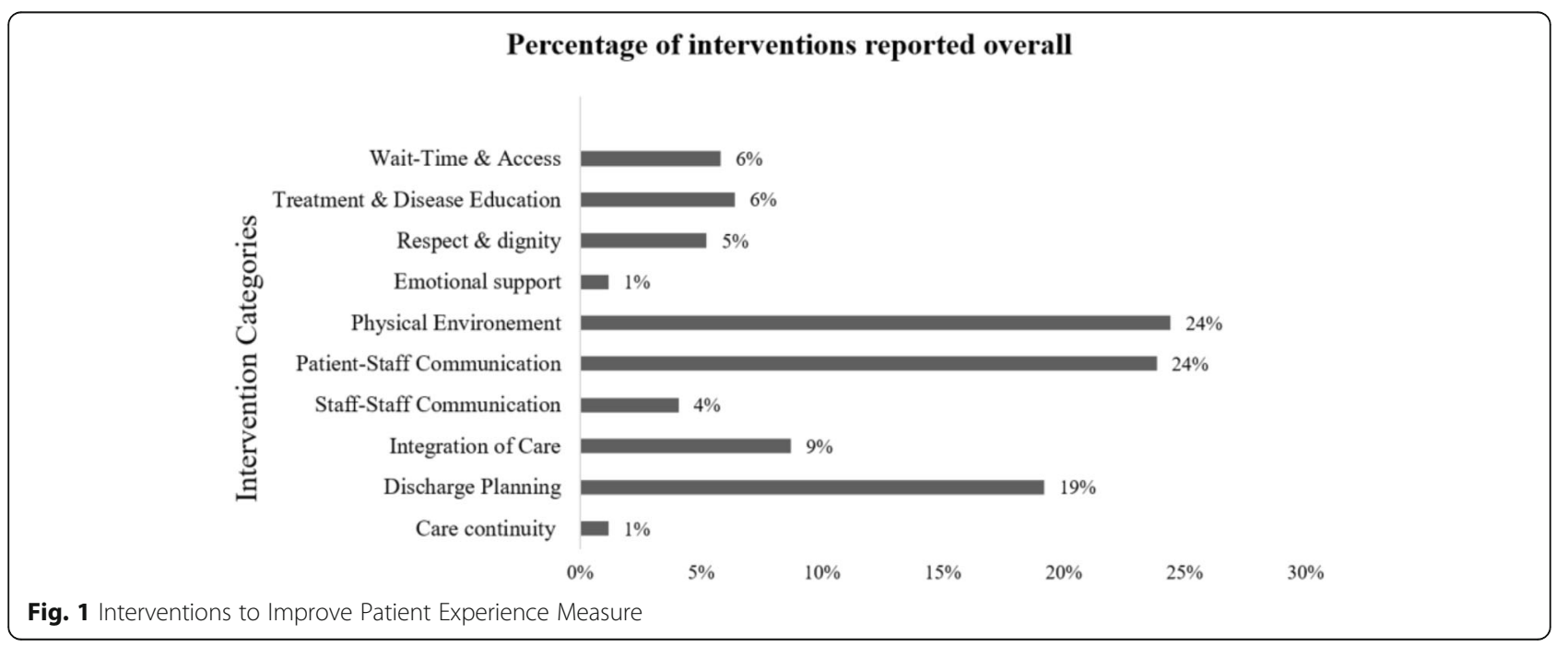


Table 5 Measure Invariance of 2016 and 2018 respondents

\begin{tabular}{|c|c|c|c|c|c|c|c|}
\hline Model Comparison & $x^{2}(d f) p$ & $\Delta x^{2}(\Delta d f) p$ & $\begin{array}{l}\Delta x^{2} \\
\Delta d f\end{array}$ & RMSEA & NFI & TLI & $\overline{\mathrm{CFI}}$ \\
\hline 1. Baseline (configural invariance) & $\begin{array}{l}2962.00(154) \\
p<0.001\end{array}$ & $19.33-$ & - & 0.04 & 0.92 & 0.91 & 0.92 \\
\hline $\begin{array}{l}\text { 2. Model 1vs. Baseline Testing Invariance of } \hat{\Lambda} \text { (weak factorial } \\
\text { invariance) }\end{array}$ & $\begin{array}{l}3008.96(165) \\
P<0.001\end{array}$ & $\begin{array}{l}46.96(11) p< \\
0.005\end{array}$ & 4.26 & 0.03 & 0.92 & 0.92 & 0.92 \\
\hline $\begin{array}{l}\text { 3. Model } 2 \text { vs. Model } 1 \text { Testing Invariance of } \hat{\tau} \text { (strong factorial } \\
\text { invariance) }\end{array}$ & $\begin{array}{l}3030.57(178) \\
P<0.001\end{array}$ & $\begin{array}{l}21.61(13) p> \\
0.051\end{array}$ & 1.74 & 0.03 & 0.92 & 0.92 & 0.92 \\
\hline $\begin{array}{l}\text { 4. Model } 3 \text { vs. Model } 2 \text { Testing Invariance of } \hat{\theta} \text { (strict factorial } \\
\text { invariance }\end{array}$ & $\begin{array}{l}3113.59(191) \\
P<0.001\end{array}$ & $\begin{array}{l}82.02(13) p< \\
0.001\end{array}$ & 6.30 & 0.03 & 0.92 & 0.93 & 0.92 \\
\hline $\begin{array}{l}\text { 5. Model } 4 \text { vs. Model } 3 \text { Testing invariance of } \hat{\psi} \text { (elegant factorial } \\
\text { invariance) }\end{array}$ & $\begin{array}{l}3117.42(192) p= \\
0.00\end{array}$ & $3.83(1) p<0.001$ & 3.83 & 0.03 & 0.92 & 0.93 & 0.92 \\
\hline
\end{tabular}

intervention was significantly higher than one or multiple interventions. This suggests that applying ineffective interventions in these areas decreased the overall patient experience.

\section{Impact of related interventions on overall patient experience measure}

The effect of categories of intervention on the overall measure of patient experience is shown in Table 7. A hierarchical regression was used. Care continuity was significant $(p<.01)$, but discharge planning was not significant. The two categories explained a negligible variance $\left(R^{2}=.001\right)$. Model tested the effects of the next category of communication. This explained a negligible increased in variance $\left(\mathrm{R}^{2}=.003\right)$. Staff-staff communication was significant $(p<.001)$; patient-staff communication was not significant. The next model on respect and dignity and emotional support significantly explained more variance in overall patient experience $\left(R^{2}=.013\right)$.

Table 6 One-Way ANOVA and T-Test of Numbers of Interventions on Overall Patient Experience

\begin{tabular}{|c|c|c|c|c|c|c|c|}
\hline \multicolumn{8}{|l|}{ One-Way ANOVA } \\
\hline $\begin{array}{l}\text { Intervention } \\
\text { category }\end{array}$ & $\frac{\text { (A) None }}{M(\mathrm{SE})}$ & $\frac{\frac{\text { (B) One }}{\text { intervention }} \mathrm{M}}{\text { (SE) }}$ & $\frac{\frac{\text { (C) Two }}{\text { interventions }}}{\text { (SE) }}$ & $\frac{\text { (D) Three }}{\text { interventions }} \mathrm{M}$ & $\frac{\text { (E) Four }}{\text { interventions }} M$ & F-ratio & $\begin{array}{l}\text { Differences } \\
\text { (Post-hoc) }\end{array}$ \\
\hline Integration of care & $\begin{array}{l}93.26 \\
(.167)\end{array}$ & $95.16(.411)$ & $96.51(.550)$ & & & $15.55^{* * *}$ & $C>B>A$ \\
\hline Discharge plan & $\begin{array}{l}93.57 \\
(.208)\end{array}$ & $93.62(.233)$ & $93.74(.677)$ & & & 0.38 & - \\
\hline Wait-time \& Access & $\begin{array}{l}93.85 \\
(.165)\end{array}$ & $92.80(.373)$ & & $90.65(1.38)$ & & $7.61^{* * * *}$ & $A>B$ \\
\hline $\begin{array}{l}\text { Staff - Staff } \\
\text { Communication }\end{array}$ & $\begin{array}{l}93.31 \\
(.163)\end{array}$ & $96.92(.362)$ & $93.66(1.02)$ & & & $21.16^{* * *}$ & $B>A \& C$ \\
\hline $\begin{array}{l}\text { Patient-Staff } \\
\text { Communication }\end{array}$ & $\begin{array}{l}93.21 \\
(.224)\end{array}$ & $95.02(.238)$ & $92.82(.361)$ & $89.50(1.36)$ & & $16.23^{* * *}$ & $B>A>C \& D$ \\
\hline Physical environment & $\begin{array}{l}93.57 \\
(.205)\end{array}$ & $93.20(.282)$ & $95.18(.417)$ & $91.51(.865)$ & $97.71(.680)$ & $7.71^{* * *}$ & $\begin{array}{l}C>A \& B \& D \quad E> \\
A \& B \& C \& D\end{array}$ \\
\hline \multicolumn{8}{|l|}{ T-Test } \\
\hline $\begin{array}{l}\text { Intervention } \\
\text { category }\end{array}$ & $\frac{\text { (A) None }}{M(\mathrm{SE})}$ & $\frac{\frac{\text { (B) One }}{\text { intervention }} \mathrm{M}}{\text { (SE) }}$ & & & & $t$ & Differences \\
\hline Care Continuity & $\begin{array}{l}93.69 \\
(.155)\end{array}$ & $91.98(.708)$ & & & & $6.36^{*}$ & $A>B$ \\
\hline Respect \& Dignity & $\begin{array}{l}93.20 \\
(.165)\end{array}$ & $96.83(.309)$ & & & & $57.17^{* * *}$ & $B>A$ \\
\hline Emotional Support & $\begin{array}{l}93.95 \\
(.156)\end{array}$ & $90.59(.551)$ & & & & $45.91^{* * *}$ & $A>B$ \\
\hline $\begin{array}{l}\text { Treatment \& } \\
\text { disease education }\end{array}$ & $\begin{array}{l}93.51 \\
(.153)\end{array}$ & $98.51(.503)$ & & & & $19.71^{* * *}$ & $B>A$ \\
\hline
\end{tabular}


Table 7 Regression Analysis Summary for Related Categories of Interventions on Overall Patient Experience

\begin{tabular}{|c|c|c|c|c|c|c|c|c|}
\hline \multirow[t]{2}{*}{ Grouped Interventions } & \multicolumn{2}{|c|}{ Model 1} & \multicolumn{2}{|c|}{ Model 2} & \multicolumn{2}{|c|}{ Model 3} & \multicolumn{2}{|c|}{ Model 4} \\
\hline & $B$ & $t$ & $B$ & $t$ & $B$ & $t$ & $B$ & $t$ \\
\hline Care Continuity & -.030 & $-2.55^{* *}$ & & & & & -.039 & $-3.21^{* * *}$ \\
\hline Discharge Plan & .005 & .460 & & & & & -.004 & -.330 \\
\hline Staff-Staff Communication & & & .057 & $4.85^{* * *}$ & & & .041 & $3.41^{* * *}$ \\
\hline Staff-Patient Communication & & & -.011 & -.96 & & & .024 & 1.79 \\
\hline Respect \& Dignity & & & & & .080 & $6.81^{* * *}$ & .085 & $7.06^{* * *}$ \\
\hline Emotional Support & & & & & -.069 & $-5.93^{* * *}$ & -.077 & $-5.65^{* * *}$ \\
\hline$R^{2}$ & .001 & & .003 & & .013 & & .017 & \\
\hline$\Delta R^{2}$ & & & .002 & & .010 & & .004 & \\
\hline
\end{tabular}

Respect and dignity was significant $(p<.001)$, and finally, emotional support was negative and significant. This suggests emotional support interventions in this study reduced overall patient experience within this group category. Perhaps this indicates that emotional support interventions required further exploration of their acceptability and adherence by the healthcare professionals and patients. Model 4, with all the categories tested, explained slightly more variance in overall patient experience $\left(R^{2}=.017\right)$. This suggests the need for prioritisation of intervention categories for their effect on overall patient experience when these categories of interventions were to be implemented.

\section{Impact of intervention on specific outcome measures}

The impact of interventions (both application and level of application) on specific outcome measures were presented in Table 8. There were significant differences in staff-patient communication outcome measure $(p<.001)$, where one intervention was significantly better than no intervention or multiple interventions. This suggests that focusing on one effective uniform communication intervention would provide a good experience for patients' interaction with staff rather than using multiple interventions. Similarly, for respect and dignity and treatment and disease education significantly higher scores in the corresponding outcome measures were found with one intervention compared to none. Conversely, emotional support, no intervention was significantly higher than one or multiple interventions, suggesting that the intervention had a negative effect. Regardless of the number of discharge planning interventions, they made no significant difference. However, the mean scores $(88-89 \%)$ of the discharge planning outcome measure across the number of interventions were all above the $75 \%$ target level set by the DHHS. The mixed findings on the physical environment could be due to the limited two questions (focusing only on cleanliness) in the outcome measure and not an accurate indicator of the changes in the physical environment. In summary, these results on specific outcome measures, are aligned with their impact on the overall patient experience measure.

\section{Relationship between overall patient experience measure and specific outcome measure}

The correlations between the specific outcome measures and overall patient experience scores for each year (2016 and 2018) separately are presented in Table 9. The outcome measures and overall patient experience $(p<.01)$ were highly correlated for both years and the correlations have generally increased in 2018 except for the

Table 8 Impact of Interventions (both application and level of application) on Corresponding Outcome Measures

\begin{tabular}{|c|c|c|c|c|c|c|c|}
\hline Interventions & $\frac{\text { (A) None } M}{\text { (SE) }}$ & $\frac{\text { (B) One level } M}{\text { (SE) }}$ & $\frac{\text { (C) Two levels } M}{\text { (SE) }}$ & $\begin{array}{l}\text { (D) Three levels } \\
\mathrm{M}(\mathrm{SE})\end{array}$ & $\begin{array}{l}\text { (E) Four levels } M \\
\text { (SE) }\end{array}$ & F-ratio & $\begin{array}{l}\text { Differences } \\
\text { (Post-hoc) }\end{array}$ \\
\hline Discharge Planning & $89.40(.326)$ & $89.21(.381)$ & $88.68(1.08)$ & & & .22 & - \\
\hline Physical environment & $94.14(.189)$ & $92.28(.283)$ & $95.97(.404)$ & $92.47(.686)$ & $97.77(.707)$ & $17.82^{* * *}$ & $E>D \& B \& A$ \\
\hline $\begin{array}{l}\text { Staff-Patient } \\
\text { communication }\end{array}$ & $87.27(.377)$ & $89.35(.447)$ & $87.26(.557)$ & $82.88(1.77)$ & & $7.49^{* * *}$ & $B>A \& C \& D A>D$ \\
\hline Respect \& dignity & $93.89(.162)$ & $96.72(.323)$ & & & & $36.41^{* * *}$ & $B>A$ \\
\hline Emotional support & $89.86(.386)$ & $86.21(1.21)$ & & & & $9.78^{* *}$ & $A>B$ \\
\hline $\begin{array}{l}\text { Treatment \& disease } \\
\text { education }\end{array}$ & $86.18(.421)$ & $97.43(1.52)$ & & & & $5.07^{*}$ & $B>A$ \\
\hline
\end{tabular}

${ }^{*}=p<.05,{ }^{* *}=p<.01,{ }^{* * *}=p<.001$ 
Table 9 Correlations of overall patient experience and specific outcome measures

\begin{tabular}{|c|c|c|c|c|c|c|c|c|}
\hline & & 2018 & & & & & & \\
\hline & & $\begin{array}{l}\text { Overall patient } \\
\text { experience }\end{array}$ & $\begin{array}{l}\text { Discharge } \\
\text { planning }\end{array}$ & $\begin{array}{l}\text { Physical } \\
\text { environment }\end{array}$ & $\begin{array}{l}\text { Staff-Patient } \\
\text { communication }\end{array}$ & $\begin{array}{l}\text { Respect \& } \\
\text { dignity }\end{array}$ & $\begin{array}{l}\text { Emotional } \\
\text { support }\end{array}$ & $\begin{array}{l}\text { Treatment \& } \\
\text { disease education }\end{array}$ \\
\hline \multirow[t]{7}{*}{2016} & $\begin{array}{l}\text { Overall patient } \\
\text { experience }\end{array}$ & & $.477^{* *}$ & $.491^{* *}$ & $.719^{* *}$ & $.609^{* *}$ & $.753^{* *}$ & $.544^{* *}$ \\
\hline & $\begin{array}{l}\text { Discharge } \\
\text { planning }\end{array}$ & $.483^{* *}$ & & $.355^{* *}$ & $.583^{* *}$ & $.425^{* *}$ & $.509^{* *}$ & $.466^{* *}$ \\
\hline & $\begin{array}{l}\text { Physical } \\
\text { environment }\end{array}$ & $.458^{* *}$ & $.314^{* *}$ & & $.472^{* *}$ & $.475^{* *}$ & $.483^{* *}$ & $.317^{* *}$ \\
\hline & $\begin{array}{l}\text { Patient-staff } \\
\text { communication }\end{array}$ & $.692^{* *}$ & $.578^{* *}$ & $.462^{* *}$ & & $.645^{* *}$ & $.819^{* *}$ & $.680^{* *}$ \\
\hline & Respect \& dignity & $.598^{* *}$ & $.423^{* *}$ & $.446^{* *}$ & $.641^{* *}$ & & $.721^{* *}$ & $.491^{* *}$ \\
\hline & Emotional support & $.748^{* *}$ & $.520^{* *}$ & $.447^{* *}$ & $.796^{* *}$ & $.705^{* *}$ & & $.626^{* *}$ \\
\hline & $\begin{array}{l}\text { Treatment \& } \\
\text { disease education }\end{array}$ & $.536^{* *}$ & $.509^{* *}$ & $.329^{* *}$ & $.700^{* *}$ & $.481^{* *}$ & $.638^{* *}$ & \\
\hline
\end{tabular}

discharge planning measure. This shows that the interventions were having a beneficial effect that is not reflected by the mean score in overall patient experience. This suggest one or other aspects of the experience could affect the overall experience, this finding is supported by findings from other studies [42, 43].

\section{Discussion}

This study found that the level of overall patient experience of the 59 health services in 2016 and 2018 was consistent (over 93\%) but below the set target (95\%). A modest increase in mean scores in nine questions from 2016 to 2018 was also found. The interventions reported were not found to change the overall patient experience scores significantly. This could suggest that the interventions contributed to the maintenance of the scores. However, to break through the plateau of the overall patient experience score, further evaluation of the interventions' efficacy and implementation is needed.

Nevertheless, in examining the categories and effect of interventions reported by health services in 2017, differences were found on the overall patient experience and specific outcome measures in the 2018 VHES scores.

The Victorian Government and DHHS had set out a state-wide design, service and infrastructure plan for the health services from 2017 to 2037 [44]. This could explain why the highest number of interventions reported by health services were in the area of improvement to the physical environment.

The next categories most frequently chosen and reported by the 59 health services were communication between staff and patients and discharge planning. Some examples of communication interventions included the introduction of communication aids such as whiteboards for staff to invite patients to ask and answer their questions, 'teach-back' method asking patients to explain in their own words the information given [45] and a campaign to remind staff to introduce themselves and their names to patients. The discharge planning interventions included the introduction of discharge planning discussion at the bedside with patients and reminders for staff to include and involve carers and families in discharge planning meetings. It was noted that respect and dignity and emotional support interventions were used least. It could suggest a lack of efficacious interventions in these areas or knowledge of them.

The results of this study provide a working basis for prioritising interventions for health services and policymakers. Firstly, by the categories or focus areas of interventions; next, the 'dosage' or number of interventions required to have an effect on overall patient experience.

When discharge planning and staff-patient communication interventions are already implemented and associated with a consistent level of overall patient experience (as in the case of this study), prioritising the focus areas of staff-staff communication and respect and dignity interventions are more likely to increase overall patient experience. However, the use of care continuity and emotional support interventions was associated with a decrease in the level of the patient experience. It is possible that the interventions were not evidence-based, fit for the context or not well implemented. Further examination of the efficacy and choice of interventions in these areas is needed. It is also possible that certain interventions require an extended implementation period, and their effect may not be evident in a year.

The next finding is about the optimal 'dosage' for interventions. When examining the 'dosage' and its effect on the overall patient experience or corresponding outcome measure, a similar pattern was observed. In targeting communication amongst staff and between staff and patients, one intervention is associated with more 
positive patient experience than multiple interventions. This was also found in the areas of respect and dignity and treatment and disease education where only single intervention was implemented and was effective. Speculatively, one well-designed and evidence-based intervention that was implemented uniformly in a health service would have a more significant impact than multiple interventions implemented in different departments. This study contributes to the body of literature on the efficacy of single versus multiple interventions [46, 47], where the evidence on the efficacy is caveat by the context and nature of the intervention. Nevertheless, in the context of the Victorian public inpatient services, using one evidence-based intervention in the areas at the point of care mentioned above is associated with improvement in overall patient experience.

\section{Strengths and limitations}

To the knowledge of the authors, this is the first study to examine and integrate the routinely collected qualitative and quantitative data on improvement efforts on patient experience in Victoria, Australia. This study identifies state-wide trends on areas and the impact of interventions on patient experience with system-level implications beyond an evaluation of intervention in pilot sites.

Another contribution is in expanding the use of the VHES instrument beyond the one question overall patient experience measure and the discharge planning measure that were used by policymakers as performance indicators. This study explored the potential of extracting other specific outcome measures from VHES to evaluate the different aspects of the patient experience. However, a review of the sensitivity of the measure could not be conducted using just the results of the survey in this study alone.

There are a few limitations to this study; the majority of the interventions focused on changing staff behaviours at the point of care and broader organisationallevel interventions were not examined and not in the scope of the study. Despite the large sample, the data were only at two points in time (2016 and 2018) and not able to measure changes or interventions that may take longer to take effect, future studies could include data from more than two years of survey to have a more indicative trend. Besides, the findings are not causal and provide no direct explanations of the mechanism behind these associations. We also cannot rule out the possibility of reporting bias since the interventions are based on self-report from the health services.

\section{Implications for health services}

For health service practitioners designing and planning future interventions for improving patient experience, there could be significant benefits to consider the areas of respect and dignity and emotional support, least targeted in this study, as they are highly correlated and account for most of the effect on overall patient experience. They were also identified in evidence-based practices and recommendations $[16,48]$ to improve patient-centred care and patient experience.

Another important consideration is the selection and design of the intervention needed in the relevant context. This could be achieved through identifying the target behaviour for change, targeting barriers faced by the staff for their practice change and using a theoryinformed intervention [49] where the mechanism of action is identified and can be tested and replicated. This may require significant time and resources to do in healthcare settings. As shown in this study, prioritising and focusing on implementing one intervention for each area instead of multiple interventions is more likely to improve outcomes and optimise resources utilisation.

\section{Implications for policy}

These findings confirm the impact of policy levers such as guidelines and funding-related performance targets on health services' quality improvement activities in patient experience. However, there are other opportunities for policymakers to support the improvement of the patient experience. Firstly, support the pilot and evaluation of evidence-based interventions in the areas of respect and dignity and emotional support to break through the plateau of patient experience scores. Secondly, encourage the appropriate 'dosage' of interventions by engaging and supporting large-scale evidence-based of a single intervention at any one time in the areas of communication, respect and dignity and treatment and disease education.

\section{Research implications}

There are still many unanswered questions about the rationale and mapping of interventions to patient experience improvement areas. Future research is needed to identify the specified behaviours to change, examine the context and barriers before mapping and choosing the interventions required. This will contribute to the body of evidence to inform the implementation of more evidence-based interventions.

\section{Conclusion}

In conclusion, this study contributes to the evidence in exploring the impact of interventions on patient experience among inpatient service users in Victoria, Australia. Despite no significant change in overall patient experience, it is encouraging that health services were maintaining a consistent level of the patient experience. It is the hope that the findings will encourage further support 
in identifying and implementing evidence-based interventions as part of routine practice. In the interim, these findings demonstrate that when the patient experience is measured as an essential aspect of health services performance, it leads to efforts at continuous improvement and recognition of the importance of patients' views.

\section{Abbreviations}

DHHS: Department of Health and Human Services; EPOC: Effective Practice and Organisation of Care; HCAHPS: Hospital Consumer Assessment of Healthcare Providers and Systems; NHS: National Health Service; VHES: Victorian Healthcare Experience Survey

\section{Supplementary Information}

The online version contains supplementary material available at https://doi. org/10.1186/s12913-021-06336-0.

Additional file 1:. Codebook of categories and description of interventions

Additional file 2:. VHES questions mapped to outcome measures

\section{Acknowledgements}

Not applicable.

\section{Authors' contributions}

EW contributed to the concept, data collection, data analysis, data interpretation and drafting the manuscript. FM and JF contributed to the concept, data interpretation and manuscript review. LH and LM contributed to the concept and manuscript review. All authors reviewed and approved the final version of the manuscript.

\section{Funding}

Sources of support: Eunice Wong is supported by a research higher degree scholarship jointly funded by the Australian Government Research Training Program and Safer Care Victoria. Jane Fisher is supported by the Finkel Professional Fellowship, funded by the Finkel Family Foundation. Beyond funding support, the funders had no direct role in the study design, data collection, analysis, or interpretation, or writing the manuscript.

\section{Availability of data and materials}

The data generated or analysed during this study available from corresponding author on reasonable request.

\section{Declarations}

Ethics approval and consent to participate

Ethics approval for this study was provided by the Monash University Human Research Ethics Committee (Project ID 20530).

\section{Consent for publication}

Not applicable.

\section{Competing interests}

The authors declare that they have no competing interests.

\section{Author details}

${ }^{1}$ BehaviourWorks Australia, Monash Sustainable Development Institute, Monash University, Melbourne, PO Box 8000, Monash University LPO, Clayton, VIC 3800, Australia. ${ }^{2}$ School of Public Health and Preventive Medicine, Monash University, Melbourne, Australia. ${ }^{3}$ Department of Marketing, Monash University, Melbourne, Australia. ${ }^{4}$ Safer Care Victoria, Department of Health, Victoria, Australia.
Received: 25 December 2020 Accepted: 30 March 2021

Published online: 07 April 2021

\section{References}

1. Agency for Health and Research and Quality. What is Patient Experience [Internet]. [cited 2018 Jul 10]. Available from: https://www.ahrq.gov/cahps/a bout-cahps/patient-experience/index.html

2. Ahmed F, Burt J, Roland M. Measuring Patient Experience: Concepts and Methods. Patient. 2014;7(3):235-41 Available from: https://link.springer. com/10.1007/s40271-014-0060-5 [cited 201930 Aug].

3. Wolf J, Niederhauser $V$, Marshburn D, LaVela S. Defining patient experience. Patient Exp J. 2014:1 Available from: https://pxjournal.org/journal/vol1/iss1/3 [cited 201920 Jan].

4. Stoelwinder JU. Final report of the National Health and hospitals reform commission: will we get the health care governance reform we need? Med J Aust. 2009;191(7):387-8. https://doi.org/10.5694/j.1326-5377.2009.tb02846.x

5. De Silva D. Helping people share decision making. London: The Health Foundation; 2012. 1-13 p. Available from: https://www.health.org.uk/public/ cms/75/76/313/3448/HelpingPeopleShareDecisionMaking.pdf?real Name= rFVU5h.pdf

6. Doyle C, Lennox L, Bell D. A systematic review of evidence on the links between patient experience and clinical safety and effectiveness. BMJ Open. 2013;3(1):e001570 Available from: https://bmjopen.bmj.com/lookup/doi/1 0.1136/bmjopen-2012-001570 [cited 201821 Aug].

7. de Silva D. Helping measure person centred care: a review of evidence about commonly used approaches and tools used to help measure personcentred care. London: The Health Foundation; 2014. 76 p. Available from: https://www.health.org.uk/sites/default/files/HelpingMea surePersonCentredCare.pdf

8. McMillan SS, Kendall E, Sav A, King MA, Whitty JA, Kelly F, et al. Patientcentered approaches to Health care: a systematic review of randomized controlled trials. Med Care Res Rev. 2013;70(6):567-96. https://doi.org/10.11 77/1077558713496318

9. Mead N, Bower P. Patient-centred consultations and outcomes in primary care: a review of the literature. Patient Educ Couns. 2002:48(1):51-61. https://doi.org/10.1016/S0738-3991(02)00099-X.

10. Anhang Price R, Elliott MN, Zaslavsky AM, Hays RD, Lehrman WG, Rybowski $L$, et al. Examining the Role of Patient Experience Surveys in Measuring Health Care Quality. Med Care Res Rev. 2014;71(5):522-54 Available from: https://www.ncbi.nlm.nih.gov/pubmed/25027409 [cited 2018 Aug 21].

11. Schoen C, Osborn R, Huynh PT, Doty M, Zapert K, Peugh J, et al. Taking The Pulse Of Health Care Systems: Experiences Of Patients With Health Problems In Six Countries. Health Aff. 2005;24(Suppl 1):W5-509 W5-525. Available from: https://www.healthaffairs.org/doi/10.1377/hlthaff. [cited 20192 Dec].

12. Coulter A, Jenkinson C. European patients' views on the responsiveness of health systems and healthcare providers. Eur J Public Health. 2005; 15(4): 355-360. Available from: https://academic.oup.com/eurpub/article/15/4/3 55/469020/European-patients-views-on-the-responsiveness-of [cited 20192 Dec]

13. Luxford K, Sutton S. How does patient experience fit into the overall healthcare picture? Patient Exp J. 2014; 1: 20. Available from: https:// pxjournal.org/journal/vol1/iss1/4 [cited 201926 Feb]

14. Patel D, De Silva D. Helping measure person-centred care [Internet]. 2014 [cited 2018 Jun 17]. Available from: www.health.org.uk/helpingmeasurepcc

15. Australian Commission on Safety and Quality in Health Care. Review of patient experience and satisfaction surveys conducted within public and private hospitals in Australia [Internet]. 2012 [cited 2018 Aug 26]. Available from: https://www.safetyandquality.gov.au/sites/default/files/migrated/ Review-of-Hospital-Patient-Experience-Surveys-conducted-by-AustralianHospitals-30-March-2012-FINAL.pdf

16. Harrison R, Walton M, Manias E. Patients' experiences in Australian hospitals: a rapid review of evidence [Internet]. 2015 [cited 2020 Aug 26]. Available from: https://www.safetyandquality.gov.au/sites/default/files/migrated/Pa tients-Experiences-in-Australian-Hospitals-rapid-review-of-the-evidence.pdf

17. Keller AC, Bergman MM, Heinzmann C, Todorov A, Weber H, Heberer M. The relationship between hospital patients' ratings of quality of care and communication. Int J Qual Heal Care. 2014;26(1):26-33 Available from: https://academic.oup.com/intqhc/article-lookup/doi/10.1093/intqhc/mzt083.

18. Burgener AM. Enhancing communication to improve patient safety and to increase patient satisfaction. Health Care Manag (Frederick). 2017;36(3):238- 
43. Available from: https://journals.Iww.com/00126450-201707000-00005. https://doi.org/10.1097/HCM.00000000000000165.

19. Dwamena F, Holmes-Rovner M, Gaulden CM, Jorgenson S, Sadigh G, Sikorskii A, et al. Interventions for providers to promote a patient-centred approach in clinical consultations. Vol. 2012, Cochrane Database of Systematic Reviews. John Wiley and Sons Ltd; 2012.

20. LaVela S, Gallan A. Evaluation and measurement of patient experience. Patient Exp J. 2014;1:28 Available from: https://pxjournal.org/journal/vol1/ iss $1 / 5$ [cited 202025 Jun].

21. The Health Foundation. Measuring patient experience [Internet]. 2013 [cited 2018 Jul 17]. Available from: https://www.health.org.uk/sites/health/files/Mea suringPatientExperience.pdf

22. Coulter A, Fitzpatrick R, Cornwell J. The Point of Care: Measures of patients' experience in hospital - The King's Fund, 2009.

23. Jenkinson C, Coulter A, Bruster S. The Picker Patient Experience Questionnaire: development and validation using data from in-patient surveys in five countries. 2002 [cited 2019 Jan 20];14(5). Available from: http://www.ncbi.nlm.nih.gov/pubmed/12389801

24. Delnoij DMJ. Measuring patient experiences in Europe: what can we learn from the experiences in the USA and England? Eur J Public Health. 2009; 19(4):354-6 Available from: https://academic.oup.com/eurpub/articlelookup/doi/10.1093/eurpub/ckp105 [cited 202019 Feb].

25. Australian Commission on Safety and Quality in Health Care. National Safety and Quality Health Service Standards Second edition Published by the Australian Commission on Safety and Quality in Health Care [Internet]. 2017 [cited 2019 Jan 19]. Available from: www.safetyandquality.gov.au

26. Robert $\mathrm{G}$, Cornwell J. Rethinking policy approaches to measuring and improving patient experience. J Health Serv Res Policy. 2013; 18(2): 67-69. Available from: https://journals.sagepub.com/doi/10.1177/1355819612473 583 [cited $201922 \mathrm{Jul}$ ]

27. Wolf JA. The State of Patient Experience 2017: A ReturnTo Purpose [Internet]. 2017 [cited 2019 Jan 20]. Available from: www.theberylinstitute. org

28. Wong E, Mavondo F, Fisher J. Patient feedback to improve quality of patient-centred care in public hospitals: a systematic review of the evidence. BMC Health Serv Res. 2020;20(1):530 Available from: https:// bmchealthservres.biomedcentral.com/articles/10.1186/s12913-020-05383-3 [cited 202013 Jun].

29. Victorian Government Department of Health. Victorian Healthcare Experience Survey - VHES [Internet]. [cited 2018 Jun 4]. Available from: https://www2.health.vic.gov.au/hospitals-and-health-services/quality-safetyservice/patient-experience-survey.

30. Victorian Government Department of Health. Victorian quality account [Internet]. [cited 2020 Jul 3]. Available from: https://www2.health.vic.gov.a u/about/participation-and-communication/quality-account.

31. Australian Governement Australian Institute of Health and Welfare. Australia's health 2018 [Internet]. Canberra, Australia; 2018 [cited 2020 Jul 3]. Available from: https://www.aihw.gov.au/reports/australias-health/australiashealth-2018/report-editions

32. Victorian Government Department of Health. Victorian quality account [Internet]. [cited 2019 Jun 30]. Available from: https://www2.health.vic.gov.a u/about/participation-and-communication/quality-account

33. Victorian Government Department of Health. Victorian Healthcare Experience Survey [lnternet]. [cited 2020 Jul 3]. Available from: https:// results.vhes.com.au/

34. Krippendorff K. Content analysis : an introduction to its methodology. 3rd ed. Sage Publications; 2012.456 p.

35. EPOC CEP and O of CRG. EPOC Taxonomy [Internet]. 2015 [cited 2019 Mar 5]. Available from: https://epoc.cochrane.org/sites/epoc.cochrane.org/files/ public/uploads/taxonomy/epoc_taxonomy.pdf

36. Yin RK. Case study research : design and methods. 5th ed. Los Angeles: SAGE; 2014

37. van der Linden WJ. Item Response Theory. In: International Encyclopedia of Education [Internet]. Elsevier; 2010 [cited 2020 Jul 26]. p. 81-8. Available from: https://linkinghub.elsevier.com/retrieve/pii/B9780080448947002505

38. State of Victoria D of $\mathrm{H}$ and $\mathrm{HS}$. Victorian health services performance monitoring framework 2018-2019 [Internet]. 2018 [cited 2019 Jun 25]. Available from: https://www2.health.vic.gov.au/hospitals-and-health-services/ funding-performance-accountability/performance-monitoring

39. Milfont TL, Fischer R. Testing measurement invariance across groups: applications in cross-cultural research. Int J Psychol Res. 2010; 3(1): 111-130.
Available from: https://revistas.usb.edu.co/index.php/IJPR/article/view/857 [cited $202018 \mathrm{Sep}$ ]

40. Mavondo FT, Farrell MA. Measuring Market Orientation: Are There Differences Between Business Marketers and Consumer Marketers? Aust J Manag. 2000;25(2):223-44 Available from: https://journals.sagepub.com/ doi/10.1177/031289620002500206 [cited 202018 Sep].

41. Bialosiewicz S, Murphy K, Berry T. An Introduction to Measurement Invariance Testing: Resource Packet for Participants Do our Measures Measure up? The Critical Role of Measurement Invariance Demonstration Session American Evaluation Association, October 2013: Washington; Claremont Evaluation Center; 2013 [cited 2019 Sep 18]. Available from: https://comm.eval.org/HigherLogic/System/DownloadDocumentFile.a shx?DocumentFileKey=63758fed-a490-43f2-8862-2de0217a08b8

42. Tanniru M, Khuntia J. Dimensions of Patient Experience and Overall Satisfaction in Emergency Departments. J Patient Exp. 2017:4(3):95-100 Available from: /pmc/articles/PMC5593258/ [cited 202116 Mar].

43. Modarresi M, Qureshi A, Aguilar R, Anderson M, Cheung F. Optimizing quality of care by patient satisfaction for the department of Orthopaedics-A survey study. Marshall J of Med. 2018;4(4) Available from: https://mds.ma rshall.edu/mjm/vol4/iss4/9 [cited 2020 Mar 16].

44. Victorian Government Department of Health. Statewide Design, Service and Infrastructure Plan for Victoria's Health System 2017-2037 [Internet]. Melbourne; 2017 Oct [cited 2020 Jul 3]. Available from: https://www2.health.vic.gov.au/ hospitals-and-health-services/health-system-design-planning/statewide-plan.

45. Tran S, Bennett G, Richmond J, Nguyen T, Ryan M, Hong T, et al. 'Teach-back' is a simple communication tool that improves disease knowledge in people with chronic hepatitis B - a pilot randomized controlled study. BMC Public Health. 2019;19(1):1355 Available from: https://doi.org/10.1186/s12889-019-7658-4.

46. Squires JE, Sullivan K, Eccles MP, Worswick J, Grimshaw JM. Are multifaceted interventions more effective than single-component interventions in changing healthcare professionals' behaviours? An overview of systematic reviews [Internet]. Vol. 9, Implementation Science. BioMed Central Ltd. 2014: 152 Available from: https://implementationscience.biomedcentral.com/a rticles/10.1186/s13012-014-0152-6 [cited 202027 Oct].

47. Haverfield MC, Tierney A, Schwartz R, Bass MB, Brown-Johnson C, Zionts DL, et al. Can patient-provider interpersonal interventions achieve the quadruple aim of healthcare? A systematic review. Vol. 35, J Gen Intern Med. Springer; 2020: p. 2107-2117. Available from: https:/doi.org/10.1007/ s1 1606-019-05525-2 [cited 202027 Oct]

48. Dwamena F, Holmes-Rovner M, Gaulden CM, Jorgenson S, Sadigh G, Sikorskii A, et al. Interventions for providers to promote a patient-centred approach in clinical consultations [Internet]. Vol. 2012, Cochrane Database of Systematic Reviews. John Wiley and Sons Ltd; 2012 [cited 2020 Aug 17]. Available from: https://doi.wiley.com/10.1002/14651858.CD003267.pub2

49. French SD, Green SE, O'Connor DA, McKenzie JE, Francis JJ, Michie S, et al. Developing theory-informed behaviour change interventions to implement evidence into practice: a systematic approach using the Theoretical Domains Framework. Implement Sci [Internet]. 2012 Apr 24 [cited 2020 Apr 20];7(1):38. Available from: https://implementationscience.biomedcentral. com/articles/10.1186/1748-5908-7-38

\section{Publisher's Note}

Springer Nature remains neutral with regard to jurisdictional claims in published maps and institutional affiliations.

Ready to submit your research? Choose BMC and benefit from:

- fast, convenient online submission

- thorough peer review by experienced researchers in your field

- rapid publication on acceptance

- support for research data, including large and complex data types

- gold Open Access which fosters wider collaboration and increased citations

- maximum visibility for your research: over $100 \mathrm{M}$ website views per year

At $\mathrm{BMC}$, research is always in progress.

Learn more biomedcentral.com/submissions 